\title{
Em busca do segredo da flor: meu aprendizado de Orissi entre Brasil, Itália e Índia
}

In search of the secret of the flower: my learning of Orissi between Brazil, Italy and India

Priscilla DUARTE ${ }^{1}$

Resumo

O texto apresenta o percurso da autora no aprendizado da dança clássica indiana Orissi, no período em que foi aluna-atriz no Teatro Tascabile di Bergamo, na Itália, e da mestra de dança clássica indiana Orissi, guru Aloka Panikar, na Índia. No texto, de inspiração autoetnográfica, a autora busca refletir sobre aspectos da formação do ator, dentro de uma perspectiva não acadêmica e transcultural.

Palavras-chave: Dança clássica indiana Orissi.

Teatro Tascabile di Bergamo. Formação do ator.

\section{Abstract}

The text presents the route of the author in the learning of indian classical dance Orissi, in the period she was a student-actress at the Teatro Tascabile di Bergamo, in Italy, and of the master of indian classical dance Orissi, guru Aloka Panikar, in India. In this text of auto-ethnographic inspiration, the author seeks to reflect on the aspects of the actor's education, from a non-academic and transcultural perspective.

Keywords: Indian classical dance Orissi.

Teatro Tascabile di Bergamo. Actor's education.
1.

Priscilla Duarte é atriz e pesquisadora, Bacharel em Artes Cênicas (UNIRIO, 1987), Mestre em Artes (UFMG, 2014) e Doutoranda em Artes, Linha de Pesquisa Artes da Cena (UFMG, desde 2015). E-mail: priduarte66@gmail.com 
A platéia mal tolera, tão monótona é esta dança já determinada há séculos. E também porque é iniludivel o nosso mal estar diante do Oriente: é um outro modo de saber a vida, o deles. E depois há o outro mal estar: sente-se que eles não acreditam em nós. Há então certos movimentos dos dançarinos que desanimam todo o Ocidente. Eles acreditam em máscaras, acreditam num amor maior: são coisas antigas, serenas demais (Lispector, 1978).

Este texto tem como tema meu aprendizado da dança clássica indiana Orissi², na Índia, com a mestra Aloka Panikar, articulado com o período em que fui allieva-attrice (aluna-atriz) do Teatro Tascabile di Bergamo (TTB) na Itália. Esse mesmo tema tem origem na minha dissertação de mestrado (Duarte, 2014), defendida em 2014. As reflexões que trago são fruto da minha experiência, conforme a acepção do termo em Larrosa (2012) a partir de Benjamin (1987) e Heidegger (1987). Parto de fatos que me aconteceram, muitos deles registrados em dezenas de cadernos de trabalho (Duarte, 1985, 1989-1994, 1989-1990), e revisitados cerca de vinte e cinco anos depois de ocorridos. À moda de Manoel de Barros (2003), são memórias que tem algo de invenção, que se constituem da subjetividade do vivido, e por isso mesmo, não se pretendem historiográficas. A inspiração metodológica foi, antes, autoetnográfica.

Considero que a possível relevância deste texto para o campo da pesquisa em Artes Cênicas resida naquilo que emerge dos entrelaçamentos entre tempo passado e tempo presente, entre culturas diferentes que se encontram, entre gerações distintas que ensinam e aprendem juntas, entre afetos que surgem de caminhos insuspeitados, entre paixão e dedicação pelo ofício. Minha formação artística constitui-se desse tecido, que vem se entrelaçando entre Brasil, Itália e Índia, desde 1989. Apresento meu percurso no intuito de fomentar discussões sobre as múltiplas possibilidades de formação do ator, incluindo a formação não acadêmica, numa perspectiva transcultural, como vem sendo, em parte, a minha.

O Tascabile di Bergamo (TTB) e a linhagem

dos teatros de grupo europeus

Fundado em 1972 na cidade de Bergamo (Itália), o TTB é um dos mais representativos teatros de grupo de sua geração (Schino, 2007). Diversamente das companhias teatrais, os tea-

Orissi é o mesmo que Odissi, estilo da dança clássica indiana originária da região de Orissa, costa Leste da Índia. Atualmente, as danças indianas consideradas clássicas são oito: Bharata Natyam, Kathakali, Manipuri, Kathatk, Orissi (ou Odissi), Kuchipudi, Mohini Attam e Sattriya (KOTHARI, 2003). O nome Odissi é mais difundido, embora nem o r nem o d traduzam exatamente o som original em língua oria, que seria, na verdade, uma mistura das duas consoantes, algo como Ordissi. Disponível em: http://urvasidance.com/ odissi/spelling.htm Acesso em 05/05/14. Nesse texto, fui fiel à mestra Aloka Panikar que usa a denominação Orissi dance (dança Orissi), ou apenas Orissi. 
tros de grupo caracterizavam-se pela ênfase na pesquisa, no processo, e não no resultado imediato. A origem do TTB está ligada a uma dupla referência: Eugenio Barba e Jerzy Grotowski. O grupo italiano nasce no contexto do Terceiro Teatro, termo cunhado por Eugenio Barba (2010) que define um movimento teatral cujas escolhas artísticas denotam posições éticas e políticas bem precisas. Oposição à estagnação do teatro institucional subvencionado, e ao teatro de vanguarda condenado à busca da originalidade, treinamento como resposta à necessidade de desenvolvimento técnico, por meio de auto-pedagogia são princípios comuns aos teatros de grupo do Terceiro Teatro. O destaque concedido aos teatros tradicionais asiáticos pela Antropologia Teatral de Barba (1993; 2012) também exerceu forte impacto sobre o TTB. De outro lado, havia a noção de Teatro Pobre de Grotowski (2011) e sua concepção de técnica como possibilidade de desenvolvimento disciplinado e preciso da criatividade.

Ao longo dos anos, o TTB desenvolveria um percurso artístico singular em busca de técnicas para o aperfeiçoamento da arte do ator, a partir da influência daqueles que Renzo Vescovi - diretor do TTB - considerava seus mestres: Barba e Grotowski (Vescovi, 2007). Essa busca enfatizou duas linhas mestras que guiariam as escolhas formativas dos atores e a poética dos espetáculos do grupo italiano - o teatro de rua (e suas técnicas correlatas, principalmente o uso das pernas-de-pau) e o teatro oriental (especialmente as danças clássicas indianas, mas também, em menor medida, o Teatro Balinês e a Ópera de Pequim).

\section{Encantamento pela dança indiana e partida para a Itália}

Nas primeiras turnês do TTB ao Brasil, em 1987 e 1988, o grupo realizou espetáculos de rua e de sala, conferências e oficinas. Os espetáculos de dança indiana e as oficinas de Orissi oferecidos pelo TTB, dos quais participei no Rio de Janeiro, exerceram sobre mim um verdadeiro encantamento. Em 1989 parti para a Itália, na intenção de consolidar no TTB o que havia aprendido nas oficinas, e de preparar-me para uma viagem de estudos à Índia. Mas, aconteceu algo bem diferente do planejado. Aos poucos, o encantamento se estendeu também ao próprio TTB, pela qualidade artística e rigor técnico (que eu tanto almejava em minha formação) praticados no grupo. O que deveria ser um estágio, acabou se convertendo numa relação de trabalho de 1989 a 1994, e depois, de colaboração, de 2003 a 2007.

Ser aluno-ator do TTB era como ser aprendiz nas botteghe d'arti (ateliês) do Renascimento. Começava-se observando, 
ajudando, fazendo pequenos favores, assumindo pequenas responsabilidades, desempenhando pequenos papéis nos espetáculos, até que se dominasse o mestiere (ofício). Além da botthega d'arte, há outra analogia que diz muito do TTB, grupo que se dedica à prática de diversas formas de teatro-dança indianos desde 1979. Trata-se do sistema de aprendizagem tradicional da Índia, definido pelo termo sânscrito gurukulam. A sílaba gu significa "sombra", obscuridade; a sílaba ru, "aquele que as dissipa"; portanto, guru é "aquele que tem o poder de dissipar as sombras da ignorância e de conduzir o aluno à luz do conhecimento". Kula é família, linhagem ou casa. Portanto, gurukulam significa "aprender na casa do guru" (Antze, 2012). Assim, o TTB foi, para mim, a casa; e seu diretor e atores ${ }^{3}$, meus (primeiros) gurus.

As ocasiões de aprendizagem apresentavam-se a todo momento. Participar como assistente dos espetáculos de rua era tão instrutivo quanto assistir a um ensaio,acompanhando as observações de Renzo Vescovi sobre as questões dos atores e da encenação. Ambas as situações, de forma diferente, propiciavam um contato direto com os problemas do fazer, do saber fazer, isto é, do ofício. Ser aluno-ator do TTB significava também ser aspirante a um lugar permanente no grupo. Por isso, havia um investimento recíproco entre o aluno-ator e os membros do grupo na relação de ensino/aprendizagem. Tratava-se de um acordo tácito, que se explicitava na mesma proporção que a relação se fortalecia, ou não. Muitos alunos passaram pelo TTB; poucos se mantiveram no grupo por mais de alguns meses.

\section{A "Índia do TTB"}

A "jornada indiana do TTB", iniciada em 1979, compreende muito mais do que a busca pelo domínio das técnicas de dança (que impulsionou as primeiras viagens do grupo à Índia); inspirou conceitos éticos e artísticos do grupo sobre a arte do ator. Ao longo dos anos, o TTB fundou sua própria tradição, "digerindo" e "metabolizando" a experiência indiana em um novo contexto. A indissociabilidade entre as noções de teatro e dança, e de ator e dançarino, conforme preconiza a Antropologia Teatral de Eugenio Barba (2012), era uma realidade no grupo italiano. Além dos espetáculos de teatro-dança clássico indiano propriamente ditos, nos estilos Orissi, Kathakali e Bharata Natyam, no TTB praticava-se natya - "a arte do teatro que dança"4 . Mesmo aquilo que não era dança indiana era tratado como se o fosse; o ator do TTB deveria ter pleno domínio do seu corpo, nos mínimos detalhes. Cada ação era absolutamente fixada em uma partitura precisa, perfeita-
3.

Quando cheguei ao TTB em 1989, o grupo era composto por Renzo Vescovi (diretor artístico) e pelos atores Beppe Chierchetti, Luigia Calcaterra, Tiziana Barbiero, Caterina Scotti, Mario Barzaghi, Alberto Gorla e Paolo Fattore. Os alunos-atores éramos eu e Ricardo Gomes, ambos do Brasil, e a italiana Anna Maestroni. Susanna Vicenzetto, Franco Pasi e Enrico Messerolli, todos ex-atores do TTB, colaboravam em projetos eventuais. O grupo continua ativo em 2015. Para outras informações, consultar www. teatrotascabile.org

4.

[...] arte del teatro che danza [...] (Savarese, 1992, p. 173). As traduções das citações em língua estrangeira são da autora. 
mente passível de repetição, quer se tratasse de cena para um espetáculo de sala, quer fosse para um espetáculo de rua, com os atores atuando sobre pernas-de-pau. Por outro lado, mesmo os espetáculos de dança indiana do TTB resultavam inevitavelmente de releituras, apropriações e deslocamentos de uma tradição outra, para a fundação de uma tradição própria. Era um processo que implicava escolhas de valores, condutas e comportamento, que seriam depois filtrados e reelaborados em novos contextos.

O TTB estabeleceu contato com o teatro oriental na Europa, no auge do movimento dos teatros de grupo dos anos 1970, que buscavam renovações culturais, políticas, éticas e técnicas do teatro. A redescoberta do corpo do ator, como meio de comunicação para além da palavra, determinou a busca de novas técnicas de treinamento (Schino, 2007). Esse contexto despertou no TTB a necessidade de busca da técnica. De acordo com Vescovi (2007), o teatro europeu e sua tradição de três séculos havia se esgotado. Penso que o principal tesouro trazido da Índia por Renzo Vescovi e seus atores foi o estranhamento de si e da própria cultura. Houve porém outro fator decisivo que moveu Renzo Vescovi, a convencer seus atores a embarcarem para a Índia depois de assistir a seu primeiro espetáculo de Orissi, com a dançarina Aloka Panikar: o desejo de possuir a beleza absoluta, ou seja, paixão (Vescovi, 2007).

A partir de 1978, em viagens anuais para estadias de alguns meses, o TTB extraiu da Índia uma espécie de "destilado de saberes tradicionais", uma espécie de "Índia do TTB": um "lugar" constituído de afeto, admiração e respeito, fonte preciosa de saberes, selecionados, porém, para atender a interesses bem precisos. Se, por um lado, o desejo de ser "filológico", como dizia Renzo Vescovi, determinava a postura paradoxal de, por vezes, "ser mais indiano que os indianos" em respeito à tradição cênica indiana, por outro, os materiais (danças, músicas, figurinos e outros) podiam ser ressignificados em outros contextos. Assim, uma coreografia de Orissi podia ser executada sobre pernas-de-pau, ao som do Minuetto de Luigi Boccherini, em cena do espetáculo de rua Valse, e tornar-se irreconhecível ao público como dança indiana.

Porém, nem sempre havia uma fronteira nítida entre essas duas posturas - a "filológica" e a "ressignificante"-; aí se localiza o que chamo de "Índia do TTB". Um exemplo concreto, que considero representativo disso, era a relação dos atores com os figurinos das danças indianas. No TTB usavam-se as pesadas anáguas do Kathakali, engomadas com papa de farinha, conforme reza a tradição, enquanto que alguns atores indianos já começavam a trocá-las por leves anáguas de plástico. No 
entanto, as mesmas pesadas anáguas, assim como o restante dos figurinos tradicionais, eram usadas pelos atores do TTB para dançar coreografias clássicas do Kathakali, sobre trampolini (pernas-de-pau curtas), em espetáculos itinerantes de rua, acessório improvável de ser encontrado em um espetáculo tradicional desse estilo de dança.

Sobre esse processo de apropriação operado pelo TTB com relação à materiais colhidos na Índia, Renzo Vescovi (2007) nos apresenta dois níveis de leitura daquilo que considerava uma troca, um escambo sem desequilíbrios ou explorações. O primeiro é afetivo, e se traduz na relação que o TTB estabeleceu com os ensinamentos recebidos de seus mestres indianos: recebe-se cultura em troca de admiração, amor e respeito. Outro nível, diz respeito a uma conotação cultural, ética e política mais ampla:

[...] no âmbito colonial, as coisas não são assim tão fáceis para mim. Mohan $[\text { Khokar }]^{5}$ dizia-me que, no fim das contas, os ingleses tinham lhes dado [aos indianos] a língua, as ferrovias e até mesmo a democracia e as instituições representativas (naturalmente que o êxito positivo foi involuntário). Do mesmo modo [...] sem o Ocidente, a dança indiana teria tido maiores dificuldades em renascer. Por fim, a vida é trabalho, às vezes fatigante, para todos. Mas, a consciência de não ter roubado ou explorado, nem de longe, nem sonhando, é tranquila ${ }^{6}$.

Transculturalismo ou interculturalismo? O que Renzo Vescovi classifica como troca, Bharucha (1996) considera uma obsessão neocolonialista dos interculturalistas ocidentais, por materiais e técnicas de disciplinas tradicionais do terceiro mundo. Na sua rusticidade, tais materiais trariam novo vigor àqueles que, fascinados, deles se utilizam sem preocupar-se com as implicações dessas apropriações; há um custo para aquelas culturas consideradas "outras" de onde esses materiais proveem. A meu ver, esse ônus de que fala Bharucha é o mesmo que mantém a hegemonia do pensamento do Norte sobre o pensamento do Sul, conforme sugere Morin (2011), em um mundo que se globaliza. Essa discussão poderia incluir também a contribuição dos estudos pós-coloniais, como assinala Almeida (2002). Porém, devo pôr fim a essa digressão, uma vez que são questões por demais amplas para serem desenvolvidas neste texto.

\section{Aprendendo Orissi no TTB e na Índia}

Meu aprendizado de Orissi desenvolveu-se conforme a lógica da "Índia do TTB". De um lado, seguia-se o rigor técnico da
$5 \cdot$

Mohan Khokar, professor, historiador pioneiro na documentação da dança indiana e autor de livros definitivos sobre o assunto, foi amigo pessoal e colaborador de Renzo Vescovi, por quem nutria grande admiração e respeito.

6.

[...] anche a livello coloniale le cose non sono così facili, per me. Mohan mi diceva in fondo gli inglesi ci hanno dato la lingua e le ferrovie, perfino la democrazia e le istituzioni rappresentative... (esito favorevole involontario, naturalmente). Allo stesso modo, [...] senza l'Occidente la danza indiana sarebbe rinata con maggiori difficoltà. Insomma la vita è lavor, a volte fatica, per tutti. Ma la coscienza di non aver rubato o sfruttato, neanche lontanamente o per sogno, è tranquila (Vescovi, 2007, p. 334). 
mestra indiana de Orissi do TTB, a dançarina Aloka Panikar. De outro, os critérios de escolha do que aprender e os tempos dessa aprendizagem eram estabelecidos por Tiziana Barbiero - atriz do TTB e minha professora de Orissi - segundo interesses do grupo. De novo a dualidade típica da "Índia do TTB". Por um lado, Orissi era importante para minha formação de atriz - a prática de um estilo de dança indiana era obrigatória a todo aluno-ator do grupo -, de outro, era interessante tornar-me apta a compôr o elenco dos espetáculos de Orissi o quanto antes. Segundo essa lógica, antes mesmo que eu tivesse aprendido os trinta e nove passos fundamentais de Orissi, Tiziana Barbiero, começou a ensinar-me uma coreografia completa do repertório clássico - o Mangalacharan Cadacit, espécie de "oração dançada" dedicada à Krishna, que muito se aproxima das origens rituais desse estilo de dança.

Com relação ao ensinamento de Orissi, o TTB construiu ao longo dos anos sua própria metodologia em diálogo com Aloka Panikar. Porém, estabelecer esse diálogo com a mestra indiana não foi tarefa simples. De acordo com Tiziana Barbiero (2007) e Luigia Calcaterra (2007) - outra atriz do TTB, que também foi minha professora de Orissi -, foi preciso ensinar Aloka Panikar a ensinar a sua dança. Tiziana Barbiero disse-me que, ao conhecer Aloka Panikar, a dança da mestra indiana parecia "instintiva". Para Luigia Calcaterra, o interesse de Aloka Panikar pela pedagogia era inexistente. Nos primeiros tempos, o método de Aloka Panikar pareceu a Tiziana Barbiero (2007, p. 281) um "não-método". Como justificativa possível para a falta de interesse e/ou de competência de Aloka Panikar para o ensino, Luigia Calcaterra considerava que a dançarina estava no auge de sua carreira, era uma celebridade no mundo da dança, e comportava-se como diva, cancelando as aulas, um a cada três dias, pelos motivos mais disparatados e fúteis. Tiziana Barbiero e Luigia Calcaterra (2007) afirmam que essa situação modificou-se com os anos, e Aloka Panikar tornou-se uma verdadeira mestra, ou seja, uma guru de Orissi (Khokar, 2011). No trecho a seguir, Tiziana Barbiero recorda suas (e de Luigia Calcaterra) experiências particulares, na primeira viagem (de três meses) das atrizes italianas à Índia em 1978:

[...] Aloka [Panikar] era uma professora iniciante, desconhecia completamente tanto rigor quanto disciplina. Encontrava sempre uma desculpa qualquer para não nos dar aula. Olhando-se no espelho, enquanto espremia uma espinha no rosto, dizia: "Tomorrow no class because, you know, I must go to the tailor" [amanhã, nada de aula, por que, vocês sabem, preciso ir ao costureiro] ou ainda: "My husband says: you too much work![sic]" [meu marido diz; você, muito trabalho!] Inesquecível! Nós ficávamos loucas porque está- 
vamos sedentas de trabalho. [...] Partimos para a Índia com a ideia de trabalhar dez horas por dia, à noite, ao amanhecer, nos horários mais impensáveis, como tínhamos lido nos livros. Esperávamos encontrar os mestres com o bastão na mão, prontos para nos punir ao primeiro erro. Que desilusão!

Ao contrário do que afirmaram Tiziana Barbiero e Luigia Calacterra, a biografia de Aloka Panikar (Khokar, 2011) sugere que ao iniciar a lecionar Orissi para as atrizes do TTB em 1978, a mestra já havia acumulado pelo menos quatorze anos de experiência ensinando na Índia. O mais correto seria afirmar que Aloka Panikar não tivesse experiência como professora de alunas ocidentais, situação que se inaugurou com as atrizes italianas, e que se tornou cada vez mais comum a partir da projeção internacional que a relação com o TTB lhe proporcionou. Se considerarmos que as italianas, em sua primeira estadia na Índia, aprenderam em três meses o mesmo que uma aluna indiana aprenderia em um ano e meio de trabalho iniciado na infância, sim, era preciso inverter a lógica, ou seja, ensinar a professora a ensinar. Mas que relação de aprendizado se estabelece quando são as alunas que fazem a professora funcionar segundo seus próprios ritmos e anseios?

Em minha primeira viagem-de-estudos de quarenta e cinco dias à Nova Delhi, em novembro de 1989, a imprecisão com o horário, a falta de pontualidade e algumas ausências sem justificativa por parte da mestra, me provocaram a mesma contrariedade que as atrizes do TTB sentiram em suas primeiras estadias com Aloka Panikar. O sentimento era de desrespeito. Naquela época, a exemplo dos outros integrantes do TTB, meu afã pelo trabalho era tal, a ponto de impedir-me de perceber que, simplesmente, Aloka Panikar e eu não tínhamos a mesma compreensão do tempo. Para além de diferenças culturais, havia também a diferença de idade; eu era uma aspirante-atriz de vinte e três anos e ela, uma dançarina consagrada de quarenta e oito. Independente da matriz cultural, acredito que o tempo é percebido de modo diverso nas diferentes fases da vida.

Hoje vejo, naquele desconforto que se revelava como um sentimento de perda de tempo, uma relação direta com o discurso de Larrosa (2014), que enumera diversos fatores que se opõem e impedem a experiência. Um desses fatores é, justamente, a falta de tempo; tudo que se passa é rápido, fragmentário, fugaz e efêmero. Tudo agita o sujeito moderno, mas nada lhe acontece. Outro fator é a frequência com que a aprendizagem é confundida com aquisição de informação. Pode-se ter informação, aprender algo, sem que nada nos aconteça ou nos toque. O rememorar e a capacidade de escuta também ficam impedidos por toda essa velocidade, e tal impedimento não permite
7.

[...] Aloka era un'insegnante

alle prime armi, rigore

e disciplina le erano del tutto sconosciuti. Trovava qualsiasi scusa per non farci lezioni. Guardandosi allo specchio, mentre si schiacciava un foruncolo, ci diceva: "Tomorrow no class because, you know, I must go to the tailor" o anche: "My husband says: you too much work!" Indimenticabile! On diventavamo matte perché eravamo acetate di lavoro. [...] Eravamo partite per l'India con l'idea di lavorare dieci ore al giorno, la notte, all' alba, negli orari più impensati, come avevamo letto sui libri. Ci aspettavamo maestri col bastone in mano pronti a punirci al primo errore. Che delusione! (Barbiero, 2007, p. 280). 
a experiência. Larrosa (2014) fala também do excesso de trabalho - entendido como afã de fazer e de modificar coisas como inimigo mortal da experiência. Esses fatores apontados por Larrosa (2014) aplicam-se, em certa medida, à relação que eu estabelecia, à época, com processos de aprendizado, como aluna-atriz do TTB e como aluna de Aloka Panikar. Era com se, para colher o conhecimento, identificado na época com desenvolvimento técnico, fosse necessário um processo extenuante, que permitisse assimilar o máximo de informação, no menor tempo possível. Talvez, se eu tivesse cedido ao ritmo de trabalho de Aloka Panikar, a experiência de aprendizado poderia ter me custado menos ansiedade e menos culpa.

Aloka Panikar era extremamente severa como professora e nunca fazia elogios. O máximo que podia conceder a um bom desempenho de suas alunas era um"not bad!’(não foi mal!). Quando ensinava um passo novo, dizia que queria vê-lo "perfect" (perfeito) na aula seguinte. No chowka (posição do "quadrado") a pelve deveria manter-se baixa, em direção ao chão - se não, ela diria logo: "sit more!" (sente mais!). No tribhanghi (posição dos "três arcos"), fazia-me notar que a pelve deveria desviar-se lateralmente, e não para trás, caso contrário, o tribhangi se tornaria "cheap" (vulgar, de mau gosto). E havia o "no unnecessary movements!"(nada de movimentos desnecessários!) para qualquer movimento que fosse involuntário. "Smile!" (sorria) era uma indicação recorrente e uma das mais difíceis de serem atendidas. O estilo Orissi tem uma expressão facial de base - um leve sorriso - que representa um dos sentimentos fundamentais descritos no Natyasastra ${ }^{8}$ : srngara ${ }^{9}$ (erótico ou amor). É o sentimento predominante nas coreografias de Orissi, cujo contexto é (quase sempre) idílico, erótico/ amoroso. A tensão excessiva, resultante do processo de automatização dos movimentos, parecia acumular-se toda no rosto, que se tornava uma "máscara rígida". Somente após a automatização dos gestos, quando não era mais necessário empregar tanto esforço na memorização, quando a "memória do corpo" começava a funcionar sozinha, de forma involuntária, era possível começar a expressar algo.

\section{O segredo do gurukulam}

Conforme Tiziana Barbiero havia me instruído antes que eu partisse para a Índia, para o bom andamento das aulas era preciso também estar bem atenta a não desapontar a mestra. Me dei conta disso de forma clara no dia em que eu deveria apresentar parte de uma nova coreografia, aprendida na véspera, e deu-se um bloqueio de memória. Tomada pelo deses-
8.

O Natyasastra é um antigo tratado sobre o teatro sânscrito, e ainda hoje referência fundamental para a cultura cênica indiana. Sua autoria é atribuída ao mítico Bharata Muni, cuja existência nunca foi comprovada historicamente. Muni quer dizer sábio, e bharata seria um acróstico de bhava (sentimento), raga (melodia) e tala (ritmo). $\mathrm{O}$ mais provável é que o texto seja o resultado da contribuição de diversos autores anônimos ao longo dos séculos. Igualmente incerta é a data de sua escritura, que pode variar, segundo diferentes historiadores, entre os sécs. VI a.C. e II d.C. (Gomes, 2007).

9.

O Natyasastra estabelece oito sentimentos (rasas) principais na arte da representação: srngara (erótico ou amor), hasya (cômico), karuna (patético), raudra (fúria), vira (heróico), bhayanaka (medo), bibbhasta (desgosto) e adbhuta (maravilha). Abhinavagupta, um comentarista do Natyasastra, acrescentou, no século $\mathrm{X}$, um nono rasa - tranquilidade (santa) - estabelecendo nove (nava) sentimentos fundamentais, os navarasa (Gomes, 2007). O rasa pode ter diversas gradações e intensidades, dependendo do personagem, da situação e das causas que levaram à expressão daquela emoção em particular (Nair; Paniker, 2009). O sentimento erótico (srngara) é usado para evocar situações favoráveis, como a primavera, entre guirlandas e ornamentos, na alegre companhia da pessoa amada em passeios no jardim, ao som de música e poesia. Deve ser representado em cena pela significativa composição entre olhos e rosto, palavras doces e divertidas, satisfação, deleite e movimentos graciosos de braços e pernas (Ghosh, 1995). 
pero, comecei a chorar. Aloka Panikar ficou tão irritada com minha atitude que, após repreender-me energicamente, retirou-se da sala e não voltou mais naquele dia. Fiquei desconcertada. Não sabia qual tinha sido sua interpretação do meu comportamento e tive receio de ter caído no conceito da minha mestra, ou pior, ter posto tudo a perder. O choque cultural explicitou-se de forma dramática. Eu não compreendia os códigos para interpretar seu comportamento e, talvez, ela também não compreendesse os meus. Para meu alívio, Aloka Panikar veio à aula normalmente no dia seguinte, mas não fez nenhuma referência ao ocorrido. Agiu como se nada tivesse acontecido e eu, prudentemente, segui seu exemplo.

Depois desse episódio, e quase no fim de minha estadia, finalmente comecei a compreender que para receber os ensinamentos, era preciso fazer por merecê-los. A sala de dança era apenas uma extensão da casa de Aloka Panikar e vice-versa; era preciso cultivar uma boa relação nos dois ambientes, que eram, na verdade, um só. Fui conquistando a atenção e a simpatia da minha mestra na medida em que demonstrava subserviência à sua autoridade, tanto em sala de aula quanto em nosso convívio cotidiano, uma vez que eu era hóspede em sua casa. Foi parte integrante desse processo prestar-lhe pequenos serviços domésticos na cozinha ou preparar-lhe a água do banho.

Para minha surpresa, para sentir-me reconhecida como discípula de minha mestra, o canal decisivo não foi (apenas) minha dedicação ao aprendizado da dança, mas outro: o afeto. Como manda a tradição, ao fim do meu período de aprendizado, ofereci um presente à minha mestra, como forma de agradecimento dos ensinamentos recebidos. Era uma roupa confeccionada por mim. Creio que o principal valor do presente não foi a roupa em si, mas o fato dessa ter sido preparada às escondidas, graças à cumplicidade de Ambika Paniker filha da mestra -, que me ajudou na escolha do tecido ao gosto da mãe, e que tinha uma máquina de costura em seu quarto. O presente permitiu conquistar, de uma só vez, a amizade da filha - que havia me ignorado até então e tornou-se minha entusiasta aprendiz de costura - e o reconhecimento da mãe, de minha condição de discípula. Ali, finalmente, compreendi o verdadeiro sentido do gurukulam.

\section{A flor, o sabor e a confissão de si}

Outro acontecimento digno de nota ocorreu anos depois, em 2005, quando Aloka Panikar veio à Itália, para um período de treinamento intensivo com as atrizes e alunas de Orissi do TTB. 
Certo dia, depois de uma de nossas aulas, Aloka Panikar pôs-se a dançar uma de suas pièce de résistence do repertório de Orissi - Yahy Malhava, um Abhinaya ${ }^{10}$ (coreografia de dança expressiva), de grande dramaticidade. Esse era um fato raro, uma vez que sua carreira de dançarina tinha sido interrompida no auge da fama, por um acidente de trânsito que lhe custou a perda do movimento de um dos olhos ${ }^{11}$. Essa limitação foi cruel, pois em Orissi, os olhos também dançam. Estranhamente, por trás daquele corpo marcado pelo sofrimento de períodos difíceis, sem o mesmo condicionamento físico de outrora (ela tinha sessenta e quatro anos nessa ocasião) e com o movimento de apenas um dos olhos, emergia forte presença e expressividade de sua dança. Como isso era possível se vários trechos da coreografia apresentavam-se imprecisos ou apenas acenados? Oida (2001) nos fornece uma pista sobre isso. Trata-se da explicação de Zeami em seu célebre tratado sobre o teatro Nô, sobre as diferenças de atuação entre atores de diferentes faixas etárias. Quando um ator passa da fase madura (entre 45 e 50 anos), é impossível reproduzir fisicamente o que fazia na juventude. Para manter o hana (literalmente, flor; complexo conceito presente no teatro Nô, que pode incluir significados como encanto e novidade) de sua arte, o ator deve basear sua interpretação em alguma coisa interna, invisível aos olhos do espectador:

Se um ator tiver aprendido como atuar real e verdadeiramente através dos anos até os 50, mesmo que a árvore esteja um pouco velha, um pouco retorcida e arqueada, ainda será capaz de produzir uma flor. Não estaremos diante de um encanto extravagante, mas de uma profunda e permanente beleza (Oida, 2001, p. 162).

Hoje, eu diria que a força que testemunhei na dança de Aloka Panikar não estava na precisão (ou na falta dela) das formas codificadas da dança Orissi, mas na capacidade de manter sua "flor". No meu entendimento, essa coisa invisível aos olhos do espectador de que nos fala Oida (2001), estava presente na dança de Aloka Panikar como uma partitura precisa de impulsos, que, como diz Grotowski (2011), iniciam-se no interior do corpo, precedendo o gesto. Porém, Grotowski (2001) considera que o treinamento dos atores orientais, voltado para o domínio técnico e mnemônico de uma espécie de alfabeto de signos do corpo, não desenvolveria os impulsos vivos do corpo. Não haveria confissão alguma nesse tipo de trabalho. E conclui: "aquilo que para nós é essencial na arte, a expressão íntima de nós mesmos, lá [no Oriente] não conta" (Grotowski, 2001, p. 164). De fato, para o ator oriental, o problema da confissão de si não se coloca.

De acordo com o Natyasastra, o fim último de natya (arte
10.

Yahi Madhava é um Abhinaya inspirado no VII canto do Gitagovinda, de Jayadeva, que conta as desventuras da pastora, devota e amante traída Radha e do seu amado, Krishna. Abhinaya é termo que define a técnica interpretativa da dança indiana, na qual a atriz-dançarina "traduz" simultaneamente, em movimento e gestos codificados, o texto da canção que acompanha a coreografia. É também o nome que indica uma das categorias de coreografias que compõe o repertório clássico. Atualmente, um espetáculo de Orissi, se compõe de: abertura, com o Mangalacharan (oração dançada de bons auspícios), seguem-se um ou mais Pallavi (coreografia de nrtta, dança pura, sem significado, de grande elaboração formal) e Abhinaya (coreografia de nrtya, dança expressiva, que conta histórias, geralmente inspiradas no Gitagovinda), e como conclusão o Moksha (que significa salvação, coreografia de nrtta, dança pura, de extrema dificuldade técnica) (Khokar e Khokar, 2011; Raut, 2007)

11.

$\mathrm{O}$ acidente de trânsito sofrido por Aloka Panikar aos 45 anos de idade, causou-lhe a paralisia de metade do corpo, além de grande trauma psicológico. Aos poucos, os movimentos do corpo voltaram, com exceção daqueles do olho. Além da interrupção precoce da carreira como dançarina, Aloka Panikar perdeu o marido e a mãe (grandes apoiadores de sua arte), nos dois anos seguintes ao acidente (Khokar, 2011). 
do teatro que dança) é proporcionar o rasa (literalmente, sabor, mas também sentimento), ou seja, a apreciação estética - o "saborear" - nos espectadores (Rangacharya, 2003). Para tanto, o ator indiano deve expressar uma combinação de diversos tipos de bhava (estados de ânimo). Rasa e bhava referem-se, portanto, a uma só experiência - natya - vivenciada sob dois pontos de vista: do espectador e do ator, respectivamente. Como se natya fosse a comida, rasa fosse seu sabor, e bhava, os ingredientes que a compõem. O rasa proporcionado por natya seria, portanto, como uma experiência sinestésica que, estimulando vários sentidos, despertaria o paladar.

Segundo essa lógica do Natyasastra, a dança que testemunhei de Aloka Panikar poderia ser considerada uma elaboração de diferentes bhavas, que cumpriu sua função de proporcionar-me rasa. Tal experiência operou em mim uma transformação. Porém, só tempos depois, ao parar para pensar no ocorrido, pude perceber que algo havia me tocado, me acontecido. Será esse o saber da experiência de que nos fala Larrosa (2014)?

De outro ponto de vista, poderia dizer também que Aloka Panikar revelou-me algo que está além da técnica, o que, claramente, não significa abandonar-se ao plasma ou ao diletantismo (Grotowski, 2001). Ao contrário, essa superação só é possível a atores que, ao atingir certo grau de experiência, são capazes de manter vivo o fluxo de impulsos de suas ações; na mestra de Orissi, esse fluxo se mantém, mesmo em idade avançada. Por isso, talvez, a dança de Aloka Panikar não tenha sido mesmo uma confissão de si, mas algo de outra natureza, de profunda e permanente beleza, que nos ultrapassa. 


\section{REFERÊNCIAS}

ALMEIDA, Miguel Vale de. O Atlântico pardo: Antropologia colonial e o caso "Zusófono" In: BASTOS, C.; ALMEIDA, M. V.; FELDMAN-BIANCO, B. (orgs.). Trânsitos coloniais: Diálogos críticos Luso Brasileiros. Lisboa: ICS, 2002.

ANTZE, Rosemary J. Exemplos orientais. In: BARBA, Eugenio; SAVARESE, Nicola (Org.). A arte secreta do ator: Um dicionário de Antropologia Teatral. São Paulo: É Realizações, 2012.

BHARUCHA, Rustom. Somebody's other. Disorientatios in the cultural politics of our times. In: PAVIS, P. The Intercultural Performance reader. London/New York: Routlege, 1996.

BARBA, Eugenio. La canoa di carta. Trattato di Antropologia Teatrale. Bologna: Il Mulino, 1993.

BARBA, Eugenio. Teatro: Solidão, Ofício, Revolta. Brasília: Teatro Caleidoscópio, 2010.

BARBA, Eugenio; SAVARESE, Nicola (Org.). A arte secreta do ator: Um dicionário de Antropologia Teatral. São Paulo: É Realizações, 2012.

BARBIERO, Tiziana. La via dell'India - 5. Tiziana Barbiero In: VESCOVI, Renzo. Scritti dal Teatro Tascabile. A cura di Mirella Schino. Roma: Bulzoni, 2007.

BARROS, M. de. Memórias inventadas: a infância. São Paulo: Planeta, 2003.

BENJAMIN, Walter. Obras escolhidas I. São Paulo: Brasiliense, 1987. In: LARROSA, Jorge. Tremores: escritos sobre a experiência. Belo Horizonte: Autêntica, 2014.

CALCATERRA, Luigia. La via dell'India - 3. Luigia Calcaterra. In: VESCOVI, Renzo. Scritti dal Teatro Tascabile. A cura di Mirella Schino. Roma : Bulzoni, 2007.

DUARTE, Priscilla. Caderno de trabalho $n^{\circ}$ 1. 1985.

DUARTE, Priscilla. Caderno de trabalho n 2. 1989 - 1994.

DUARTE, Priscilla. Caderno de trabalho Índia. 1989 - 1990.

DUARTE, Priscilla de Q. O treinamento do ator: do corpo como instrumento ao corpo como experiência. 2014. Dissertação (Mestrado em Artes). Escola de Belas Artes - Universidade Federal de Minas Gerais.

GOMES, Ricardo. Kathakali vesham - l'apprendistato dell'attore Kathakali. 2007. Tese (Dottorato in Storia, Teoria e Tecnica del Teatro e dello Spettacolo) - "La Sapienza". Università degli Studi di Roma. Roma, 2007.

GROTOWSIKI, Jerzy; FLASZEN, Ludwik. Exercícios. In: O Teatro laboratório de Jerzy Grotowski 1959 -1969. São Paulo: Perspectiva/SESC-SP/Fondazione Pontedera, 2001. 
GROTOWSKI, Jerzy; FLASZEN, Ludwik. A voz. In: O Teatro laboratório de Jerzy Grotowski 1959 -1969. São Paulo: Perspectiva/ SESC-SP/Fondazione Pontedera, 2001.

GROTOWSIKI, Jerzy. Para um teatro pobre. Organização de Eugenio Barba. Brasília: Caleidoscópio/Dulcina, 2011.

GOSH, Manomohan. (Trans.). The Natyasastra. Calcutta: Manisha Granthalaya, 1995.

HEIDEGGER, Martin. De camino al habla. Barcelona : Ediciones del Serbal, 1987. In: LARROSA, Jorge. Tremores: escritos sobre a experiência. Belo Horizonte: Autêntica, 2014.

KHOKAR, Ashish. Guru Aloka Panikar: Orissi Odyssey - The Dance History Column. Narthaki. Bangalore, jan. 4, 2011. Disponivel em: http://www.narthaki.com/info/tdhc/tdhc25.html Consultado em: 20/0J/14.

KHOKAR, Ashish; KHOKAR, Mohan. The dance Orissi. New Delhi: Bhinav, 2011.

KOTHARI, Sunil. New directions in Indian dance. Mumbai: Marg, 2003.

LISPECTOR, Clarice. Notas sobre dança hindu. In: Para não esquecer. Rio de Janeiro: Rocco, 1978.

MORIN, Edgar. Para um pensamento do sul. In: Para um pensamento do sul: diálogos com Edgar Morin. Rio de Janeiro: SESC Departamento Nacional, 2011.

NAIR, Appukuttan.; PANIKER, Ayyappa. Kathakali The Art of the Non-wordly. Mumbai: Marg, 2009.

OIDA, Yoshi. O ator invisível. Colaboração de Lorna Marshall. São Paulo: Beca produções Culturais, 2001.

RANGACHARYA, Adya. The Natyasatra - English Translation with Critical Notes. New Delhi: Munshiram Manoharlal, 2003.

RAUT, Madhumita. Odissi: What, Why \& How. New Delhi: B.R. Rhythms, 2007.

SCHINO, Mirella. Introduzione. In: VESCOVI, Renzo. Scritti dal Teatro Tascabile. A cura di Mirella Schino. Roma: Bulzoni, 2007.

SAVARESE, Nicola. Le Reincarnazioni de Sakuntala - Primi contatti con $i$ teatri d'Asia tra Illuminismo e Romanticismo. 7 . Teatri in India In: SAVARE, N. Teatro e spettacolo fra Oriente e Ocidente. Roma-Bari : 1992.

VESCOVI, Renzo. Scritti dal Teatro Tascabile. A cura di Mirella Schino. Roma: Bulzoni, 2007. 